\title{
Article
}

\section{Long-Term Outcomes of Surgical Aortic Valve Replacement in Patients with Rheumatoid Arthritis}

\author{
Markus Malmberg ${ }^{1, *,+}$, Antti Palomäki ${ }^{2,3,4,+} \mathbb{D}$, Jussi O. T. Sipilä ${ }^{5,6} \mathbb{D}^{\mathbb{D}}$, Päivi Rautava ${ }^{7,8}$, Jarmo Gunn ${ }^{1}$ and \\ Ville Kytö 1,9,10,11,12 (D)
}

1 Heart Center, Turku University Hospital and University of Turku, 20520 Turku, Finland; jarmo.gunn@tyks.fi (J.G.); ville.kyto@utu.fi (V.K.)

2 Centre of Rheumatology and Clinical Immunology, Division of Medicine, Turku University Hospital, 20520 Turku, Finland; antti.palomaki@tyks.fi

3 Department of Medicine, University of Turku, 20520 Turku, Finland

4 Institute for Molecular Medicine Finland, FIMM, HiLIFE, University of Helsinki, 00290 Helsinki, Finland

5 Department of Neurology, North Karelia Central Hospital, Siun Sote, 80210 Joensuu, Finland; jussi.sipila@utu.fi

6 Clinical Neurosciences, University of Turku, 20520 Turku, Finland

7 Department of Public Health, University of Turku, 20520 Turku, Finland; paivi.rautava@tyks.fi

8 Turku Clinical Research Centre, Turku University Hospital, 20520 Turku, Finland

9 Research Center of Applied and Preventive Cardiovascular Medicine, University of Turku, 20520 Turku, Finland

10 Center for Population Health Research, Turku University Hospital and University of Turku, 20520 Turku, Finland

11 Administrative Center, Hospital District of Southwest Finland, 20520 Turku, Finland

12 Department of Public Health, Faculty of Medicine, University of Helsinki, 00014 Helsinki, Finland

* Correspondence: markus.malmberg@tyks.fi; Tel.: +358-2-313-0000; Fax: +358-2-313-3682

check for updates

Citation: Malmberg, M.; Palomäki, A.; Sipilä, J.O.T.; Rautava, P.; Gunn, J.; Kytö, V. Long-Term Outcomes of Surgical Aortic Valve Replacement in Patients with Rheumatoid Arthritis. J. Clin. Med. 2021, 10, 2492. https://doi. org $/ 10.3390 /$ jcm10112492

Academic Editor: Burkhard Möller

Received: 25 April 2021

Accepted: 2 June 2021

Published: 4 June 2021

Publisher's Note: MDPI stays neutral with regard to jurisdictional claims in published maps and institutional affiliations.

Copyright: (c) 2021 by the authors. Licensee MDPI, Basel, Switzerland. This article is an open access article distributed under the terms and conditions of the Creative Commons Attribution (CC BY) license (https:/ / creativecommons.org/licenses/by/ $4.0 /)$.
+ Markus Malmberg and Antti Palomäki contributed equally to this paper.

Abstract: Background: Patients with rheumatoid arthritis (RA) have increased risk of developing cardiovascular disease and events. Little is, however, known about the influence of RA to the outcomes after surgical aortic valve replacement (SAVR). Methods: In a retrospective, nationwide, multicenter cohort study, RA patients $(n=109)$ were compared to patients without RA $(n=1090)$ treated with isolated SAVR for aortic valve stenosis. Propensity score-matching adjustment for baseline features was used to study the outcome differences in a median follow-up of 5.6 years. Results: Patients with RA had higher all-cause mortality (HR 1.76; CI 1.21-2.57; $p=0.003$ ), higher incidence of major adverse cardiovascular events (HR 1.63; CI 1.06-2.49; $p=0.025$ ), and they needed more often coronary artery revascularization for coronary artery disease (HR 3.96; CI 1.21-12.90; $p=0.027$ ) in long-term follow-up after SAVR. As well, cardiovascular mortality rate was higher in patients with RA $(35.7 \%$ vs. $23.4 \%, p=0.023)$. There was no difference in 30 -day mortality ( $2.8 \%$ vs. $1.8 \%, p=0.518$ ) or in the need for aortic valve reoperations ( $3.7 \%$ vs. $4.0 \%, p=0.532)$. Conclusions: Patients with rheumatoid arthritis had impaired long-term results and increased cardiovascular mortality after SAVR for aortic valve stenosis. Special attention is needed to improve outcomes of aortic valve stenosis patients with RA after SAVR.

Keywords: aortic valve stenosis; surgical aortic valve replacement; cohort study; outcomes; rheumatoid arthritis

\section{Introduction}

Rheumatoid arthritis (RA) is a chronic autoimmune inflammatory disease affecting primarily the joints but with frequent systemic and extra-articular manifestations [1]. In these patients, cardiovascular disease has been recognized as a major cause of increased morbidity and mortality [2]. Valvular abnormalities including granulomatous involvement resembling rheumatoid nodules along with valvular calcification and thickening are more 
frequently observed in patients with RA [3-6]. However, there is currently very limited evidence regarding RA patients treated with valvular surgery and especially with aortic valve stenosis. Previous studies have indicated that RA does not increase in-hospital mortality after transapical (TAVR) or surgical aortic valve replacement (SAVR) [7,8], but there are no studies about the long-term results of these procedures on RA patients. Therefore, we investigated the outcomes of SAVR for aortic valve stenosis in patients with RA.

\section{Patients and Methods}

\subsection{Study Design and Population}

Aortic valve stenosis patients treated with first-time isolated SAVR between 1 June 2005 and 31 December $2017(n=8308)$ were retrospectively recognized from the Care Register for Healthcare in Finland. This mandated-by-law, nationwide registry includes data on all hospital admissions and major surgical procedures in Finland [9]. SAVR was performed in eight hospitals (two private and six public) during the study period. Patients aged $<50$ years, patients with prior cardiac surgery, endocarditis, emergency operation, concomitant surgery of other heart valves, aorta, or coronary artery bypass, patients treated with aortic valve homograft, and patients with unspecified prosthesis type were excluded from the study. Six patients were lost to follow-up. Patients with RA were recognized from the database using ICD-10 codes M05 and M06 for seropositive and seronegative RA, respectively. To increase the specificity of RA diagnosis, only RA patients with at least two episodes with RA diagnosis in specialized care were included, resulting in 109 patients with and 3804 without RA (Figure 1).

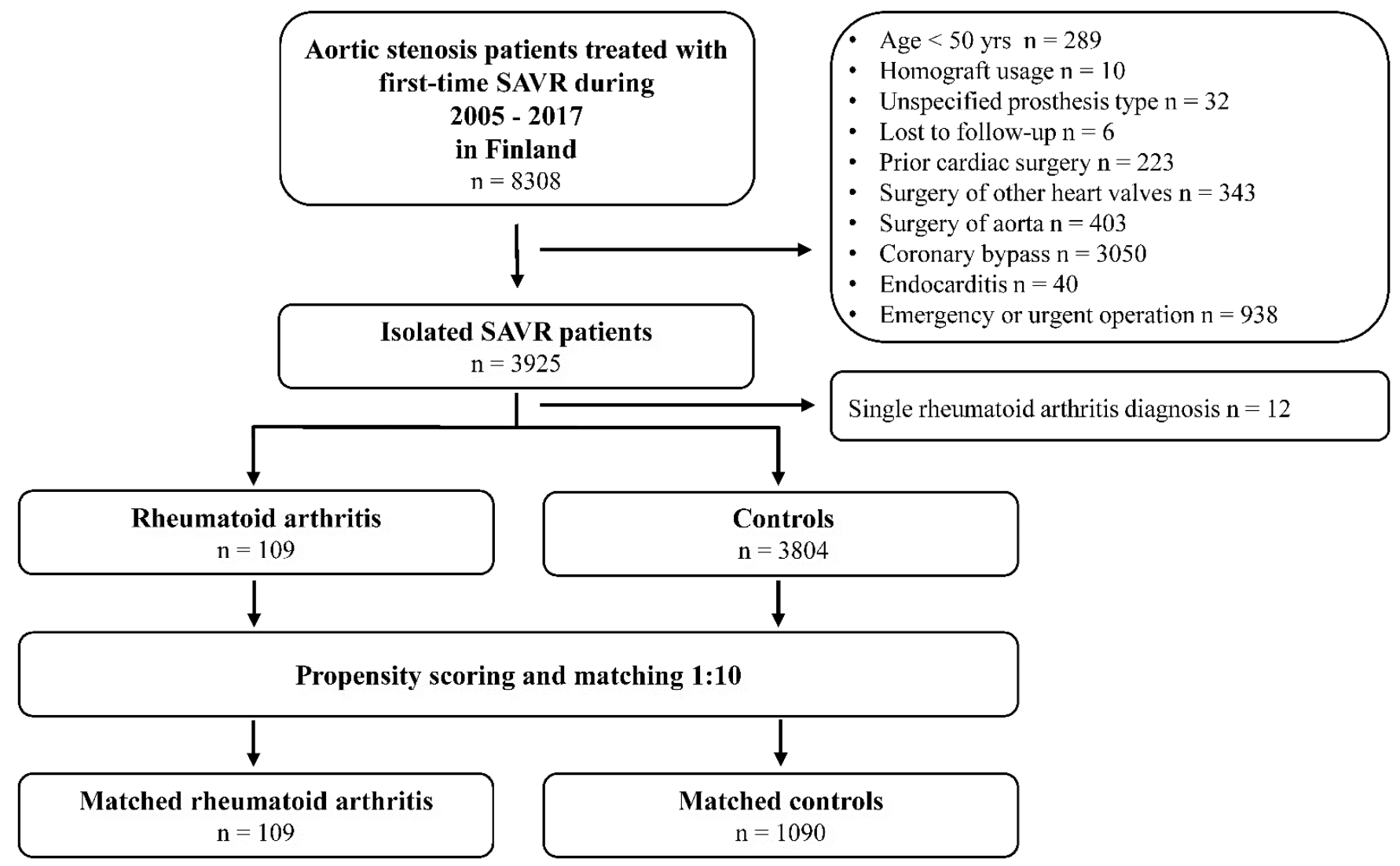

Figure 1. Study flow chart. SAVR = Surgical aortic valve replacement.

\subsection{Definitions}

The primary outcome of interest was 10-year all-cause mortality. Secondary outcomes were major adverse cardiovascular event (MACE; defined and myocardial infarction, stroke, or cardiovascular death), aortic valve related reoperation, and coronary artery revascular- 
ization within 10 years from primary surgery. In addition, 5-year interim analyses were performed. The outcomes were recognized from admission records and death certificates (Supplement methods). Comorbidities were recognized from the Care Register for Healthcare and the Finnish Cancer Registry using previously described ICD coding [10]. Mortality data were obtained from the nationwide cause of death registry held by Statistic of Finland. Follow-up ended on 31 December 2018.

\subsection{Matching and Statistical Analysis}

Propensity score based on baseline characteristics (Table 1) was created using logistic regression. Included variables were considered relevant based on literature review and clinical judgement. Patients with non-overlapping propensity scores were excluded ( $\mathrm{n}=255$ patients without RA). Trimmed propensity score was used for local optimal 1:10 caliber matching without replacing using 0.10 caliper width of the logit of standard deviation [11]. Unmeasured confounding was estimated by calculating the E-value as previously described [12]. Effect sizes of baseline characteristics between study groups were evaluated by standardized mean difference scores (SMD). Outcomes were studied with Kaplan-Meier method and Cox regression. Matched regression models were used in analysis of propensity-matched groups. In addition, multivariable Cox models adjusted with the same variables used for propensity scoring were studied in the non-matched cohort. Influence of prosthetic valve type on associations between RA status and outcomes was studied with interaction-term analysis. Association of seropositivity with long-term mortality was studied using Cox regression in RA patients adjusted for baseline features (Table 1). Proportional hazard assumptions were examined by visual examination of Schoenfeld residuals. Cause-specific hazard models for competing risk due to death were applied in analysis of other long-term outcomes. Results are given as the mean, median, percentage, or hazard ratio (HR) with $95 \%$ confidence intervals (CI). $p$ value $<0.05$ was inferred statistically significant. Analyses were performed with SAS version 9.4 (SAS Institute Inc., Cary, NC, USA).

Table 1. Baseline features of rheumatoid arthritis and control patients with isolated surgical aortic valve replacement for aortic stenosis. All and propensity score matched patients. SMD = Standardized mean difference.

\begin{tabular}{|c|c|c|c|c|c|c|}
\hline & \multicolumn{3}{|c|}{ Original Cohort } & \multicolumn{3}{|c|}{ Matched Cohort } \\
\hline & Rheumatoid Arthritis & Control & & Rheumatoid Arthritis & Control & \\
\hline Variable & $n=109$ & $\mathrm{n}=3804$ & |SMD | & $\mathrm{n}=109$ & $\mathrm{n}=1090$ & |SMD | \\
\hline Age, years (SD) & $71.7(8.0)$ & 70.7 (8.7) & 0.13 & $71.7(8.0)$ & $71.8(8.4)$ & 0.02 \\
\hline Female sex & $70(64.2 \%)$ & $1835(48.2 \%)$ & 0.33 & $70(64.2 \%)$ & $685(62.8 \%)$ & 0.07 \\
\hline Comorbidities & & & & & & \\
\hline Atrial fibrillation & $22(20.2 \%)$ & $863(22.7 \%)$ & 0.06 & $22(20.2 \%)$ & $235(21.6 \%)$ & 0.08 \\
\hline Cerebrovascular disease & $13(11.9 \%)$ & $391(10.3 \%)$ & 0.05 & $13(11.9 \%)$ & $128(11.7 \%)$ & 0.01 \\
\hline $\begin{array}{c}\text { Chronic pulmonary } \\
\text { disease }\end{array}$ & $22(20.2 \%)$ & $439(11.5 \%)$ & 0.24 & $22(20.2 \%)$ & $209(19.2 \%)$ & 0.03 \\
\hline Diabetes & $12(11.0 \%)$ & $640(16.8 \%)$ & 0.17 & $12(11.0 \%)$ & $120(11.0 \%)$ & 0.01 \\
\hline Heart failure & $27(24.8 \%)$ & $890(23.4 \%)$ & 0.03 & $27(24.8 \%)$ & $235(21.6 \%)$ & 0.08 \\
\hline Hypertension & $45(41.3 \%)$ & $1683(44.2 \%)$ & 0.06 & $45(41.3 \%)$ & $507(46.5 \%)$ & 0.09 \\
\hline Malignancy & $17(15.6 \%)$ & $451(11.9 \%)$ & 0.11 & $17(15.6 \%)$ & $158(14.5 \%)$ & 0.01 \\
\hline $\begin{array}{c}\text { Peripheral vascular } \\
\text { disease }\end{array}$ & $6(5.5 \%)$ & $210(5.5 \%)$ & 0.001 & $6(5.5 \%)$ & $64(5.9 \%)$ & 0.004 \\
\hline Psychotic disorder & $1(0.9 \%)$ & $32(0.8 \%)$ & 0.01 & $1(0.9 \%)$ & $6(0.6 \%)$ & 0.02 \\
\hline $\begin{array}{l}\text { Prior myocardial } \\
\text { infarction }\end{array}$ & $8(7.3 \%)$ & $259(6.8 \%)$ & 0.02 & $8(7.3 \%)$ & $69(6.3 \%)$ & 0.04 \\
\hline Renal failure & $1(0.9 \%)$ & $73(1.9 \%)$ & 0.09 & $1(0.9 \%)$ & $10(0.9 \%)$ & 0.05 \\
\hline $\begin{array}{l}\text { Type of aortic valve } \\
\text { prosthesis }\end{array}$ & & & 0.33 & & & 0.06 \\
\hline Biological & $87(79.8 \%)$ & $2727(71.7 \%)$ & & $87(79.8 \%)$ & $902(82.8 \%)$ & \\
\hline Mechanical & $22(20.2 \%)$ & $1077(28.3 \%)$ & & $22(20.2 \%)$ & $188(17.3 \%)$ & \\
\hline Surgical center $(n=8)$ & & & 0.10 & & & 0.03 \\
\hline
\end{tabular}




\section{Results}

Of all included aortic valve stenosis patients (median age 72 years, $48.7 \%$ women), $2.8 \%$ had RA. Patients with RA were older, more frequently women, and had higher proportion of pulmonary disease than SAVR patients without RA (Table 1). RA patients received more often biological aortic valve prosthesis. Propensity matching (1:10) identified 109 RA and 1090 control patients with comparable baseline features (Table 1). The majority of RA patients (85.3\%) were seropositive. Median follow-up time for survivors was 5.6 years (min 1.05 , max 10.0) with no difference between study groups $(p=0.703)$.

\subsection{Mortality}

During the follow-up, there were a total of 292 deaths (36 in the RA group). Thirty-day mortality in operated patients was $2.8 \%$ in the RA group vs. $1.8 \%$ in controls $(p=0.518)$. After the early post-operative period, the survival of RA patients and non-RA patients differentiated increasingly with higher long-term mortality in the RA group (Figure 2). Five-year mortality was $26.9 \%$ in the RA group and $16.4 \%$ in controls $(p=0.038)$. The mortality rate at the end of the 10-year follow-up was after SAVR was $60.5 \%$ in RA patients and $39.1 \%$ in controls (HR 1.76; CI 1.21-2.57; $p=0.003$ ). The E-value was 2.92 (CI: 1.71-4.58). Type of prosthetic valve did not have a significant influence on association of RA with higher long-term mortality (interaction $p=0.150$ ). Seropositivity was not associated with long-term mortality in RA patients in univariate (HR 0.97; $p=0.095$ ) or baseline adjusted analysis (HR 1.42; $p=0.510$ ). Results of multivariable regression models were comparable to those of the propensity-matched cohort (Supplement Table S1).

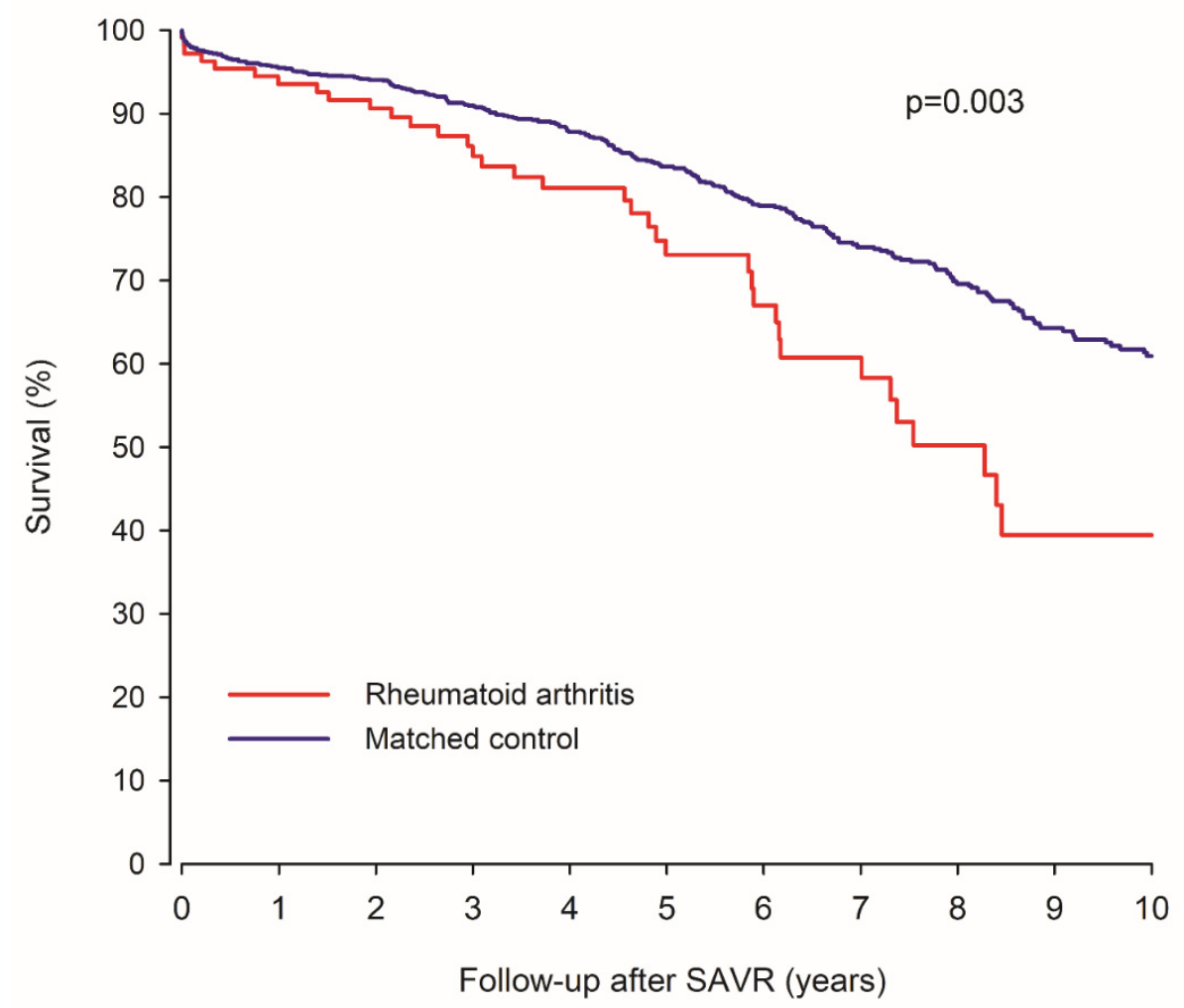

At risk

$\begin{array}{lcccccc}\text { RA } & 109 & 88 & 61 & 33 & 17 & 5 \\ \text { Control } & 1090 & 951 & 704 & 465 & 279 & 140\end{array}$

Figure 2. Survival of surgically treated aortic valve stenosis patients with rheumatoid arthritis and matched control patients. $\mathrm{RA}=$ Rheumatoid arthritis. SAVR $=$ Surgical aortic valve replacement. 


\subsection{MACE}

Major adverse cardiovascular event occurred to 255 (27 in the RA group) during the follow-up. RA and control patients had comparable MACE rates up to three years after SAVR, but thereafter the occurrence of MACE continues to increase at a higher rate in RA patients (Figure 3). At 5-year follow-up, $28.6 \%$ of RA patients and $16.3 \%$ of controls have had MACE $(p=0.041)$. The cumulative MACE rate at 10 -year follow-up was $55.2 \%$ in RA patients vs. 36.1\% in matched controls (HR 1.63; CI 1.06-2.49; $p=0.025$ ). The stroke rate during follow-up was $19.1 \%$ in RA and $16.8 \%$ in control patients $(p=0.288)$. The myocardial infarction (MI) rate during follow-up was $24.1 \%$ in RA patients and $8.2 \%$ in controls during follow-up ( $p=0.093)$. The cardiovascular mortality rate was $35.7 \%$ in RA and $23.4 \%$ in control patients (HR 1.94; CI 1.10-3.43; $p=0.023$ ). Results of the five-year interim analyses are presented in Supplementary Table S2. The type of prosthetic valve did not have significant interaction with association of RA and MACE, stroke, MI, or cardiovascular death (interaction $p>0.580$ for all). Seropositivity was not associated with MACE or its components in RA patients in ( $p>0.810$, in both univariate and multivariate analysis).

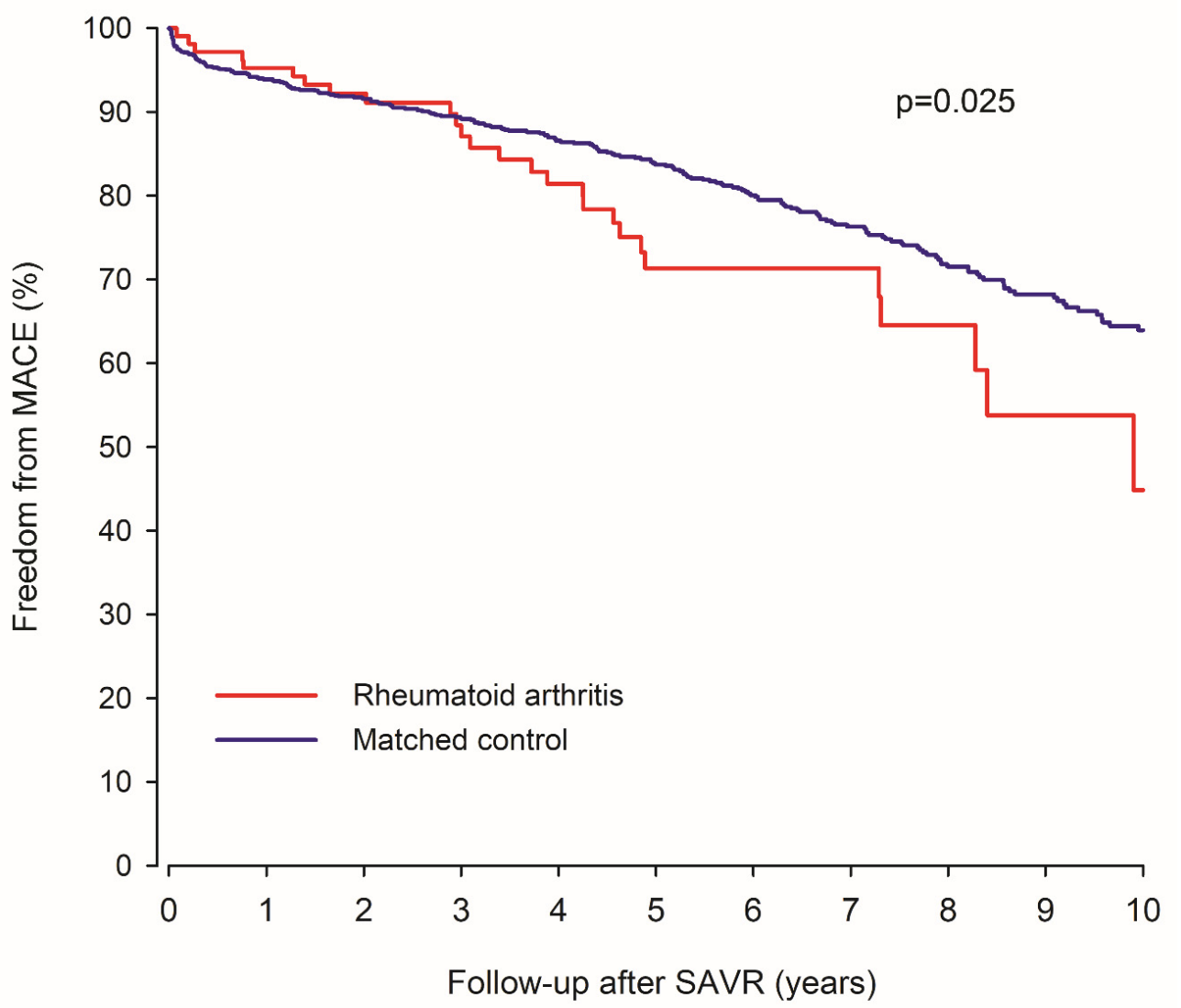

At risk

$\begin{array}{lrrrrrr}\text { RA } & 109 & 83 & 55 & 30 & 15 & 4 \\ \text { Control } & 1090 & 890 & 647 & 419 & 241 & 126\end{array}$

Figure 3. Freedom from major adverse cardiovascular event (MACE) in surgically treated aortic valve stenosis patients with rheumatoid arthritis and matched control patients. RA = Rheumatoid arthritis. SAVR = Surgical aortic valve replacement.

\subsection{Reoperation}

Aortic valve-related reoperation was performed (cumulatively) to $3.7 \%$ of RA patients and to $4.0 \%$ of control patients during the follow-up $(p=0.532)$. The type of prosthetic valve did not influence the lack of association between RA aortic valve-related reoperation 
(interaction $p=0.992)$. The majority of the reoperations $(76.9 \%)$ were surgical aortic valve reoperations. During the follow-up, coronary artery revascularization was performed to $10.3 \%$ of RA patients and to $4.3 \%$ of control patients who had no need for concomitant coronary artery bypass grafting surgery in the index procedure (HR 3.96; CI 1.21-12.90; $p=0.027$ ). The type of prosthetic valve did not influence the associations between RA and aortic valve reoperation or revascularization (interaction $p=0.992$ and 0.996 respectively). Seropositivity was not associated with reoperations or revascularization in RA patients ( $p>0.797$ in both univariate and multivariate analysis).

\section{Discussion}

This nationwide multicenter retrospective cohort study shows that patients with RA had increased mortality, greater incidence of MACE, and needed more often coronary artery revascularization during 10-year follow-up after isolated SAVR for aortic valve stenosis. In addition, cardiovascular death was more common in patients with RA.

The current evidence regarding outcomes after aortic valve replacement in patients with RA is limited. Rudasill et al. studied the short-term outcomes after TAVR in patients with connective tissue diseases, resulting with a lower 30-day mortality, but the risks for post-operative infection and septicemia were increased [7]. In their cohort of 2557 patients, $75.6 \%$ had RA [7]. In a report by Elbadawi et al., in-hospital mortality was studied after TAVR and SAVR in patients with RA, finding no difference between the two treatment options [8]. To our knowledge, our report was the first study investigating the long-term outcomes of RA patients treated with SAVR for aortic valve stenosis.

In studies regarding mitral valve, Stulak et al. compared 36 patients with RA to 72 patients without RA after mitral valve repair in a median follow-up of 4.2 years [13]. In their study, patients with RA had decreased survival $(27 \%$ vs. $64 \%, p=0.005)$ and increased risk for reoperation (freedom from reoperation $93 \%$ vs. $98 \%, p=0.04$ ) [13]. In a study by Vassileva et al., the researchers did not find a difference in in-hospital mortality after mitral valve surgery in patients with RA [14]. These results highlight the need for long-term follow-up studies in order to have more accurate data on this entire patient cohort.

Overall, valvular heart diseases are more common in patients with RA, but they are often mild and asymptomatic [3,5,15]. In a follow-up study of patients with mild and moderate aortic valve stenosis, the progression rate to more severe stenosis was not increased in patients with RA when compared to general population [16]. As the incidence of aortic stenosis in highly age-dependent [17], also RA patients presenting with symptomatic aortic valve stenosis are typically elderly with multiple comorbidities, as our study indicated.

In our study, we found out that patients with RA had higher cardiovascular mortality and needed more often revascularization for coronary artery disease in long-term. Therefore, it is possible that our results might be explained at least in part by the higher incidence of coronary artery disease in the RA cohort developed during the post-operative follow-up period. Moreover, there seems to be no difference in valve-related reoperations indicating a similar rate of structural valve degeneration, although the majority $(80 \%)$ of all implanted valves where bioprostheses. It has not been clearly indicated that RA would act as an independent risk factor for early structural valve degeneration, although inflammation itself seems to play a key role in destruction of heart valves [18,19].

Higher revascularization rate in our study indicates that the development of symptomatic cardiovascular disease is more common after SAVR in these patients. As we know from previous studies, the most common cardiac manifestations of RA are associated with atherosclerosis [20], with an increased risk of MI and cardiovascular death [2,21], making the prevention of atherosclerosis one of the key priorities in the treatment of RA patients [22]. Fortunately, there are signs that the excess cardiovascular mortality in patients with RA has decreased significantly during recent decades [23,24], possibly because of more safe and efficient RA therapies and more focus on cardiovascular prevention [25]. The prognosis of symptomatic aortic valve stenosis is extremely poor without treatment [26,27]. 
Thus, importantly, our results should not be interpreted in the way that would result in exclusion of RA patients from interventional treatment for aortic valve stenosis.

Our study has limitations. First, the retrospective nature of the study limits the possibility to interpret the results. The data that we used were collected from reliable registries, mandated by law in Finland, but it is, however, possible that sources of bias are present [28]. Coding errors are possible since diagnoses were determined by clinicians. The incidence of RA patients in this study $(2.8 \%)$ is comparable to previously reported in SAVR population (4\%) [6]. Second, more detailed information regarding in-hospital or operative data, RA disease activity or duration, pharmacotherapy of RA or cardiovascular diseases, or laboratory results were not available due to nature of available registries. Pharmacotherapies have also evolved during the 12-year recruitment period. However, it is not expected that this would have significant impact to the major findings of this study. Third, to balance the differences between the study groups, we used propensity-score matching. Although it is one of the strongest control cofounding factors, it is still possible that unrecognized residual co-founders may impact the results. Based on the E-value, the observed higher all-cause mortality in RA patients could be explained away by an unmeasured confounder that was associated with both RA and the outcome by a risk ratio of 2.9-fold each, above and beyond the measured confounders, but weaker confounding could not do so [12]. Fourthly, discovering the mediators of poorer outcome in RA patients were beyond the current study.

In conclusion, patients with RA are at higher risk of long-term all-cause mortality and MACE and need more often coronary artery revascularization after SAVR for aortic valve stenosis than patients without RA. Special attention and further studies are required to improve the outcomes of this vulnerable patient population.

Supplementary Materials: The following are available online at https:/ /www.mdpi.com/article/ 10.3390/jcm10112492/s1, Table S1: Results of unadjusted and multivariable adjusted Cox-models, Table S2: Five-year interim outcome results.

Author Contributions: Conceptualization, V.K., M.M., A.P.; methodology, V.K., J.O.T.S.; software, V.K.; validation, V.K., J.G.; formal analysis, V.K.; investigation, M.M., A.P., V.K.; resources, V.K., P.R.; data curation, V.K., P.R.; writing—original draft preparation, M.M., A.P., V.K.; writing—review and editing, M.M., A.P., J.G., P.R., J.O.T.S., V.K.; visualization, V.K.; supervision, V.K.; project administration, V.K.; funding acquisition, V.K. All authors have read and agreed to the published version of the manuscript.

Funding: This study was supported by grant funding from the Finnish Cultural Foundation, and the Finnish Governmental VTR-funding. The funding sources did not have involvement in study design; in the collection, analysis and interpretation of data; in writing of the report; or in the decision to submit the article for publication.

Institutional Review Board Statement: This study was conducted according to the guidelines of the Declaration of Helsinki and approved by the National Institute for Health and Welfare of Finland (permission No: THL/2245/5.05.00/2019) and Statistics Finland (TK-53-484-20). Legal basis for processing of personal data is public interest and scientific research (EU General Data Protection Regulation 2016/679 (GDPR), Article 6(1)e and Article 9(2)(j); Data Protection Act, Sections 4 and 6).

Informed Consent Statement: This was a retrospective register study, and no informed consent was thus required. The participants were not contacted.

Data Availability Statement: The data and study materials will be made available to those who fulfill requirements of applicable Finnish laws and regulations for purposes of reproducing the results or replicating the procedure (from the corresponding author).

Conflicts of Interest: Markus Malmberg has received travel grants and congress sponsorship (Abbott, Boston Lifesciences, Medtronic). Antti Palomäki has received grants from the Finnish Medical foundation, Finnish foundation for Cardiovascular Research and Turku University Hospital research foundation, consulting fees from Pfizer, lecture fees from MSD, Pfizer and Sanofi, and travel expenses from Bristol-Myers-Squib and Novartis. Jussi Sipilä has received Honoria (Merck, Pfizer, Sanofi), 
has served in an advisory board (Medaffcon/gmp-oprhan), has received travel grants and congress sponsorship (Abbvie, Orion Pharma, Novartis), and holds shares (Orion Corporation). Päivi Rautava none. Jarmo Gunn has received an unrestricted research grant from Vifor Pharma. Ville Kytö has received scientific consultancy fees (AstraZeneca), speaker fees (Bays, Boehringer-Ingelheim, Roche), and travel grants and congress sponsorship (AstraZeneca, Boehringer-Ingelheim, Bayer, Pfizer).

$\begin{array}{ll}\text { Abbreviations } \\ \text { RA } & \text { Rheumatoid arthritis } \\ \text { CAD } & \text { Coronary artery disease } \\ \text { TAVR } & \text { Transcatheter aortic valve replacement } \\ \text { SAVR } & \text { Surgical aortic valve replacement } \\ \text { MACE } & \text { Major adverse cardiovascular event } \\ \text { SMD } & \text { Standardized mean difference } \\ \text { HR } & \text { Hazard ratio } \\ \text { CI } & 95 \% \text { confidence intervals } \\ \text { MI } & \text { Myocardial infarction }\end{array}$

\section{References}

1. Smolen, J.S.; Aletaha, D.; McInnes, I.B. Rheumatoid arthritis. Lancet 2016, 388, 2023-2038. [CrossRef]

2. Lee, K.S.; Kronbichler, A.; Eisenhut, M.; Lee, K.H.; Shin, J.I. Cardiovascular involvement in systemic rheumatic diseases: An integrated view for the treating physicians. Autoimmun. Rev. 2018, 17, 201-214. [CrossRef] [PubMed]

3. Corrao, S.; Messina, S.; Pistone, G.; Galvo, L.; Scaglione, R.; Licata, G. Heart involvement in Rheumatoid Arthritis: Systematic review and meta-analysis. Int. J. Cardiol. 2013, 167, 2031-2038. [CrossRef]

4. Iveson, J.M.I.; Thadani, U.; Ionescu, M.; Wright, V. Aortic valve incompetence and replacement in rheumatoid arthritis. Ann. Rheum. Dis. 1975, 34, 312-320. [CrossRef] [PubMed]

5. Corrao, S.; Salli, L.; Arnone, S.; Scaglione, R.; Amato, V.; Cecala, M.; Ligata, A.; Ligata, G. Cardiac involvement in rheumatoid arthritis: Evidence of silent heart disease. Eur. Heart J. 1995, 16, 253-256. [CrossRef] [PubMed]

6. Yiu, K.H.; Wang, S.; Mok, M.Y.; Ooi, G.C.; Khong, P.L.; Lau, G.S.; Tse, H.F. Relationship between cardiac valvular and arterial calcification in patients with rheumatoid arthritis and systemic lupus erythematosus. J. Rheumatol. 2011, 38, 621-627. [CrossRef]

7. Rudasill, S.E.; Sanaiha, Y.; Xing, H.; Mardock, A.L.; Khoury, H.; Jaman, R.; Ebrahimi, R.; Benharash, P. Association of autoimmune connective tissue disease and outcome in patients undergoing transcatheter aortic valve implantation. Am. J. Cardiol. 2019, 123, 1675-1680. [CrossRef]

8. Elbadawi, A.; Ahmed, H.M.A.; Mahmoud, K.; Mohamed, A.H.; Barssoum, K.; Perez, C.; Mahmoud, A.; Ogunbayo, G.O.; Omer, M.A.; Jneid, H.; et al. Transcatheter aortic valve implantation versus surgical aortic valve replacement in patients with rheumatoid arthritis (from the nationwide inpatient database). Am. J. Cardiol. 2019, 124, 1099-1105. [CrossRef]

9. Kytö, V.; Myllykangas, M.E.; Sipilä, J.; Niiranen, T.J.; Rautava, P.; Gunn, J. Long-term Outcomes of Mechanical Vs Biologic Aortic Valve Prosthesis in Patients Older Than 70 Years. Ann. Thorac. Surg. 2019, 108, 1354-1360. [CrossRef]

10. Malmberg, M.; Sipilä, J.; Rautava, P.; Gunn, J.; Kytö, V. Outcomes After ST-Segment Versus Non-ST-Segment Elevation Myocardial Infarction Revascularized by Coronary Artery Bypass Grafting. Am. J. Cardiol. 2020, 135, 17-23. [CrossRef]

11. Quan, H.; Sundararajan, V.; Halfon, P.; Fong, A.; Burnand, B.; Luthi, J.C.; Saunders, D.; Beck, C.A.; Feasby, T.E.; Ghali, W.A. Coding algorithms for defining comorbidities in ICD-9-CM and ICD-10 administrative data. Med. Care 2005, 43, 1130-1139. [CrossRef]

12. Vander Weele, T.J.; Ding, P. Sensitivity analysis in observational research: Introducing the e-value. Ann. Intern. Med. 2017, 167, 268-274. [CrossRef] [PubMed]

13. Stulak, J.M.; Suri, R.M.; Matteson, E.L.; Dearani, J.A.; Connolly, H.M.; Schaff, H.V. Mitral valve repair is durable in patients with rheumatoid arthritis. Ann. Thorac. Surg. 2012, 94, 510-515. [CrossRef] [PubMed]

14. Vassileva, C.M.; Kwedar, K.; Boley, T.; Markwell, S.; Hazelrigg, S. Mitral valve procedure selection and outcomes in patients with rheumatoid arthritis. J. Heart Valve. Dis. 2013, 22, 14-19.

15. Grimaldi, A.; de Gennaro, L.; Vermi, A.C.; Pappalardo, F.; Brunetti, N.D.; Biase, M.D.; la Canna, G.; Alfieri, O. Cardiac valve involvement in systemic diseases: A review. Clin. Cardiol. 2013, 36, 117-124. [CrossRef] [PubMed]

16. Bois, J.P.; Crowson, C.S.; Khullar, T.; Achenbach, S.J.; Krause, M.L.; Mankad, R. Progression rate of severity of aortic stenosis in patients with rheumatoid arthritis. Echocardiography 2017, 34, 1410-1416. [CrossRef]

17. Eveborn, G.W.; Schirmer, H.; Heggelund, G.; Lunde, P.; Rasmussen, K. The evolving epidemiology of valvular aortic stenosis. the Tromsø Study. Heart 2013, 99, 396-400. [CrossRef]

18. Shetty, R.; Pibarot, P.; Audet, R.; Janvier, R.; Dagenais, F.; Perron, J.; Couture, C.; Voisine, P.; Després, J.P.; Mathieu, P. Lipidmediated inflammation and degeneration of bioprosthetic heart valves. Eur. J. Clin. Investig. 2009, 39, 471-480. [CrossRef]

19. Levine, A.J.; Dimitri, W.R.; Bonser, R.S. Aortic regurgitation in rheumatoid arthritis necessitating aortic valve replacement. Eur. J. Cardiothoracic. Surg. 1999, 15, 213-214. [CrossRef] 
20. Ferguson, L.D.; Siebert, S.; McInnes, I.B.; Sattar, N. Cardiometabolic comorbidities in RA and PsA: Lessons learned and future directions. Nat. Rev. Rheumatol. 2019, 15, 461-474. [CrossRef]

21. Aviña-Zubieta, J.A.; Choi, H.K.; Sadatsafavi, M.; Etminan, M.; Esdaile, J.M.; Lacaille, D. Risk of cardiovascular mortality in patients with rheumatoid arthritis: A meta-analysis of observational studies. Arthritis Care Res. 2008, 59, 1690-1697. [CrossRef]

22. Semb, A.G.; Ikdahl, E.; Wibetoe, G.; Crowson, C.; Rollefstad, S. Atherosclerotic cardiovascular disease prevention in rheumatoid arthritis. Nat. Rev. Rheumatol. 2020, 16, 361-379. [CrossRef] [PubMed]

23. Myasoedova, E.; Gabriel, S.E.; Matteson, E.L.; Davis, J.M., 3rd; Therneau, T.M.; Crowson, C.S. Decreased cardiovascular mortality in patients with incident rheumatoid arthritis (RA) in recent years: Dawn of a new era in cardiovascular disease in RA? J. Rheumatol. 2017, 44, 732-739. [CrossRef]

24. Kerola, A.M.; Nieminen, T.V.M.; Virta, L.J.; Kautiainen, H.; Kerola, T.; Pohjolainen, T. No increased cardiovascular mortality among early rheumatoid arthritis patients: A nationwide register study in 2000-2008. Clin. Exp. Rheumatol. 2015, 33, 391-398. [PubMed]

25. Agca, R.; Heslinga, S.C.; van Halm, V.P.; Nurmohamed, M.T. Atherosclerotic cardiovascular disease in patients with chronic inflammatory joint disorders. Heart 2016, 102, 790-795. [CrossRef]

26. Otto, C.M.; Prendergast, B. Aortic-valve stenosis-From patients at risk to severe valve obstruction. N. Eng. J. Med. 2014, 371, 744-756. [CrossRef] [PubMed]

27. Leon, M.B.; Smith, C.R.; Mack, M.; Miller, D.C.; Moses, J.W.; Svensson, L.G.; Tuzcu, E.M.; Webb, J.G.; Fontana, G.P.; PARTNER Trial Investigators; et al. Transcatheter aortic-valve implantation for aortic valve in patients who cannot undergo surgery. N. Eng. J. Med. 2010, 363, 1597-1607. [CrossRef]

28. Sund, R. Quality of the Finnish Hospital Discharge Register: A systematic review. Scand. J. Public Health 2012, 40, 505-515. [CrossRef] 